\title{
An Analysis of Vocational Interests for Female Research and Development Managers
}

\author{
RAYMOND E. HiLl \\ Graduate School of Business Administration, University of Michigan \\ AND \\ Jo-IDA C. HANSEN \\ University of Minnesota
}

\begin{abstract}
An occupational interest scale was constructed for female research and development managers utilizing a criterion sample of 201 subjects. One hundred five occupations were scored on the resulting scale in an attempt to better understand the interest structure of the criterion group. In addition, female research and development managers were compared to technical specialist groups, male research and development (R\&D) managers, and nontechnical managers. Major findings indicated female and male $R \& D$ managers were strikingly similar and both groups have task oriented rather than social-emotional leadership styles. In addition, female R\&D managers are distinguished from their technical counterparts by scoring higher in the Enterprising area. In comparison to nontechnical managers the female managers scored lower in the Enterprising area. These results were discussed in terms of their implications for technical management and career development. 1986 Academic Press. Inc.
\end{abstract}

A new emphasis on scientific research, driven by a generalized concern that American industry has slipped in its ability to innovate, has led to more concern in many organizations regarding the selection, development, and career counseling of their scientific and engineering work force (Norman, 1983). In addition, there are more attempts from several sources to increase the number of women entering scientific and engineering careers, as well as management careers (Badawy, 1982; U.S. Department of Labor, 1982). Women are underrepresented in science and engineering

Requests for reprints should be sent to Dr. Raymond E. Hill, Graduate School of Business Administration, University of Michigan, Ann Arbor, MI 48109-1234. The authors express appreciation to Dr. David P. Campbell of the Center for Creative Leadership and to Dr. Bernard Rimland of the U.S. Naval Personnel Research Laboratory for their assistance in data collection. 
as well as management (Fitzgerald \& Betz, 1983), and female research and development (R\&D) managers thus represent a highly unique occupational group. In a sense, they have pioneered twice by entering an occupational role which represents the intersection of two traditionally male-dominated career areas.

Furthermore, they are worthy of study because of the unique career problems associated with the transition from technical specialist to manager. This transition often involves a major shift in psychosocial identity and represents a choice point about which many technical specialists are highly ambivalent (Zaleznik, Dalton, \& Barnes, 1970). Simply stated, not all scientists and engineers are temperamentally suited for managerial work. The issue of enhancing the careers of female scientists and engineers could therefore be addressed more insightfully if more was known about the temperament of female R\&D Managers relative to their technical counterparts.

It is not enough, however, to generate more knowledge of how female R\&D managers compare to technical specialists. It is also important to understand the differential psychology of female R\&D managers and managers in general. Bailyn (1985) has been arguing for some time that R\&D laboratories need more pluralistic career systems. Her thesis is that most $R \& D$ organizations have career procedures which are unsatisfying to both technical specialists and R\&D managers. Since most laboratories manage their employees in too homogeneous a way, they lose the advantage of the very diversity they need. As incumbents move up the R\&D management hierarchy, for instance, there is a critical change at some point in which the key to success shifts away from influencing a subordinate group and toward influencing other parts of the organization. This is referred to as breakpoint leadership and involves influencing the strategic direction of the organization, exercising influence across many organizational boundaries, and selling top management on new research directions (McCall, 1981). It places a heavy emphasis on political and diplomatic skills and requires being able to exercise social power without guilt. Stated in somewhat different terms, managers at the top of the R\&D hierarchy have to function much like managers in general and less like technical managers. Thus, if scientists and engineers progress to top levels in the R\&D hierarchy they must undergo a complex evolutionary process from specialists to technical manager to manager in general.

A last concern if one is interested in pluralistic career systems is the degree of similarity in temperament patterns of female and male R\&D managers. While there are no extant studies comparing female and male R\&D managers, there are a large number of studies directed at male managers (Campbell, Dunnette, Lawler, \& Weick, 1970; Kotter, 1982; Miner \& Miner, 1977) and an increasing number directed at female managers (Hennig \& Jardim, 1977; McClane, 1980). Furthermore, an emerging 
trend suggests that male and female managers exhibit more similarities than differences. Donnell and Hall (1980) studied 1000 female and 1000 male managers and found no essential differences in how they managed. Brief and Oliver (1976) found no significant pattern of male-female differences on attitudinal variables among sales managers. Gough (1984) reports on a managerial potential scale which was found to be diagnostic of behavioral effectiveness, self-confidence, cognitive clarity, and goal orientation for both sexes. These latter adjectives are strikingly similar to those used by Fitzgerald and Betz (1983, p. 116) to describe careeroriented women, particularly those pursuing male-dominated occupations. They note a pattern of instrumentality, assertiveness, self-confidence, competence, and internalized bases of self-evaluation as characteristic of career women. This suggests a large proportion of pioneer women are likely to exhibit the traits necessary for managerial work, and that female and male managers will be characterized by homogeneity. Therefore, an interesting question involves the degree of similarity between male and female R\&D managers on traits pertinent to managerial work.

The purpose, then, of this study was to assess the vocational interest patterns of female R\&D managers and to compare them to the interest patterns of selected technical specialist groups, male R\&D managers, and managers in general.

\section{METHOD}

Subjects

The male and female R\&D managers in this study were the criterion groups used for constructing the R\&D manager occupational scales for the 1985 revision of the Strong-Campbell Interest Inventory. To qualify for the study, respondents had to (a) be between 25 and 60 years of age; (b) have at least a baccalaureate degree in engineering, physical science, mathematics, information science, or life science; (c) have at least 2 years of experience in research or development managment; (d) report being "satisfied" or "very satisfied" with their work; and (e) aspire to a further career in $R \& D$ management.

The sample of female research and development managers was obtained through a commercially available list of 2000 female R\&D managers published by Hugo Dunhill Mailing Lists, Inc. An additional list of 70 names was obtained by working with the EEO coordinators of eight U.S. Naval laboratories. An explanatory letter, questionnaires, and postagepaid return envelopes were then sent to the total list of 2070 soliciting educational background, job responsibilities, job title, age, tenure in the managerial role, satisfaction, and other selected background information. A total of 564 subjects responded, but only 201 qualified after applying the criterion group constraints listed above. Background information on the final criterion group of 201 female subjects includes average age, 38 
years; average education, 18 years, and average tenure in R\&D management, 5 years. With respect to educational background, the sample was distributed as follows across four general areas: $10 \%$, engineering; $34 \%$, physical sciences; $11 \%$, mathematics and information science; $45 \%$, life sciences. Respondents were distributed by management level as follows: $5 \%$, vice president; $18 \%$, upper management; $43 \%$, middle management; and $34 \%$, lower management.

The male R\&D manager criterion group was collected by surveying a broad range of scientific and engineering-based firms, primarily from the Midwest, East Coast, and West Coast. The surveys were distributed through the vice president of research and development in each of 12 firms. Three hundred twenty-five questionnaires were distributed, 256 were returned, and 215 were usable after applying the criterion group constraints. Background information on the final group of male R\&D managers includes average age, 44 years; average education, 18 years; and average tenure in $R \& D$ management, 10 years. The sample was distributed as follows across four general educational areas: $57 \%$, engineering; $27 \%$, physical sciences; $6 \%$, mathematics and information sciences; $10 \%$, life sciences. And management levels were distributed as follows: $5 \%$, vice president; $39 \%$, upper management; $45 \%$, middle management; and $10 \%$, lower management.

Data on managers in general were obtained through a secondary source (Campbell \& Van Velsor, 1985). Data on 1036 managers participating in a 1-week leadership development program from 1979 to 1982 were obtained by the Center for Creative Leadership. Sixty-five percent of the participants were from industry and business, and the remaining 35\% were from governmental and nonprofit institutions. The average age was 41 years. Fifteen percent had high school diplomas or some college, $43 \%$ held bachelors' degrees, $29 \%$ masters' degrees, and 13\% had doctoral degrees or other advanced work. They were distributed across management levels as follows: $22 \%$, top executives; $37 \%$, upper middle; $33 \%$, lower middle; $7 \%$, first level. Information on educational area was not available. Eightysix percent of the sample was male and $14 \%$ was female.

\section{Instrument}

The 1981 version of the Strong-Campbell Interest Inventory (Form 325 of the SVIB-SCII) was used to assess the interests of the male and female R\&D groups, since it served as input data generally for the 1985 revision. The secondary data source from Campbell and Van Velsor (1985) used both the 1974 and 1981 versions. In all cases the instrument has four sets of scales: (a) six General Occupational Themes that measure general interests hypothesized by Holland's theory of occupational types; (b) 23 Basic Interest Scales that are more precise interest areas within each of the six general themes; (c) 162 Occupational Scales that measure 
the interests of women and men in 85 different occupations; and (d) two Special Scales that measure Academic Comfort and Introversion-Extroversion. The Strong inventory booklet includes 325 items representing a wide variety of occupations, school subjects, leisure and work activities, types of people, and self-characteristics. These items have remained the same from 1974 through the 1985 revision.

The inventory is used extensively in research as the instrument chosen to operationalize occupational interests (Buros, 1978) and is one of the most widely used inventories in a variety of applied settings with varied clientele (Zytowski \& Warman, 1982).

\section{Data Analyses}

Two studies were conducted using the interest data collected for the 201 female R\&D managers. In Study 1, the empirical method of contrast groups was used to construct an Occupational Scale to measure the interests of female R\&D managers. One hundred five occupational samples were then scored on the resulting scale for comparison of high and low scores. Study 2 examined the interest patterns of the female R\&D managers by comparing them to scientific and engineering groups, male R\&D managers, and managers generally, on the General Occupational Themes and selected Basic Interest Scales of the SCII.

\section{Study 1: Scale Construction}

The empirical scale construction was conducted by the University of Minnesota's Center for Interest Measurement Research using the method of contrast groups which involves comparing the item response percentage rates of a criterion sample, in this case female $R \& D$ managers, to the item response percentage rates of a contrast group, in this case womenin-general. The 1985 women-in-general sample was drawn from a pool of 794 subjects from 93 different occupations. All subjects were employed adults between the ages of 25 and 60 , who liked their occupations. This represents the standard technology for vocational interest scale construction using the SCII-SVIB. Sixty-one items that differentiated the female R\&D manager criterion sample from the women-in-general contrast sample by $19 \%$ or greater were selected for inclusion in the scale. Test-retest reliability coeficients were computed for 2-week, 30-day, and 3-year intervals using standard reliability groups from the Center for Interest Measurement Research. Concurrent validity was assessed using Tilton's (1937) percentage overlap statistic applied to the scores for female R\&D managers and women-in-general. In addition, 105 occupational samples from the 1985 SCII were scored on the female R\&D manager scale, and the high and low scoring occupational groups were examined. By knowing which occupational groups were similar and dissimilar to female R\&D managers, thematic inferences could be made regarding their interest structures. 


\section{Study 2: Analyses of Interest Patterns}

The structure and pattern of interests of the female R\&D managers were further studied in three ways. First, their mean scores on the General Occupational Themes, selected Basic Interest Scales, Academic Comfort and Introversion-Extroversion were compared with selected scientific and engineering occupational groups. These groups were again the criterion samples used for interest scale construction by the Center for Interest Measurement Research, and included female physicists, chemists, mathematicians, biologists, geologists, and engineers. Second, female R\&D managers were compared to male $R \& D$ managers on the same scales listed above. And third, females were also compared to nontechnical managers, again on the same scales.

Two-tailed $t$ tests were used to assess the level of statistical significance for all comparisons, and Bonferroni's method was used to adjust the overall Type I error rate (Neter \& Wasserman, 1974, p. 480). The Type I error rate for individual pairwise comparisons was set at .00001 which made the overall Type I error rate less than .001 . This is admittedly a highly conservative procedure; however, it was done for two reasons: first, the focus of the analysis was more of true psychological differences, not just statistically significant differences; and second, comparisons were approached with relative selectivity, rather than with broad spectrum "data snooping." Using the above statistical rules translated into differences of 4 scale unit points being judged significant, and in samples larger than 30,4 scale units represent strong psychological and behavioral differences on the scales under study.

\section{RESULTS}

\section{Study 1: Scale Construction}

Test-retest reliability coefficients for the female $R \& D$ manager scale over all three time periods were as follows: two-weeks, .92; thirty-day, .88 ; three-year, .88 . This indicates the scale is highly stable over short and long periods of time. In addition, the Tilton $Q$ statistic was 2.03, indicating only $31 \%$ overlap between the female criterion sample and women-in-general sample. This reflects significant discriminant validity, and implies the means of these two comparison groups are approximately 2 standard deviation units apart on the scale.

Examples of significant discriminating items which female R\&D managers endorsed include chemist, performing scientific experiments, business magazines, and prefer technical responsibility (in charge of 25 people doing scientific work) vs supervisory responsibility (in charge of 300 people doing business-office work). Examples of significant items indicating what female R\&D managers reject include courtroom Stenographer, receptionist, and social worker (relative to statistician) and juvenile parole officer (relative to dog trainer). 
Inspection of 105 occupational samples scored and rank ordered on the female R\&D manager scale indicated the scientific, technical, and realistic occupations with high educational requirements score most similarly to R\&D managers, whereas social and artistic occupations score least similarly. Enterprising occupations ranged from middle to low ranks. Also, the high-scoring occupations $(M>40)$ endorsed science and mathematics, while the low-scoring occupations $(M<30)$ endorsed human service motives, one-on-one helping, meeting the public, teaching, and clerical activities. The higher ranked management occupations were those with a relatively high degree of professionalism, and included investments manager $(M=37)$, marketing executive $(M=33)$, and naval officer $(M$ $=32$ ). The respective Holland codes for these groups are EIC, EI, and $\mathrm{RI}$. The lower ranked management occupations included restaurant manager $(M=24)$, store manager $(M=21)$, and food service manager $(M=$ 22). The Holland codes for these three occupations are EC, EC, and $\mathrm{CS}$, respectively. This suggests indirectly that the managerial motives of female $R \& D$ managers are bound to the investigative domain. The Holland code for female R\&D managers was IR and did not directly incorporate the enterprising theme.

\section{Study 2: Comparison to other Occupational Groups}

Table 1 provides insights of a different type. Prior results have focused primarily on internal thematic analysis by utilizing the vocational interest scale. Table 1 compares female R\&D managers to six other female scientific and technical occupations on General Occupational Themes, Basic Interest Scales from the Enterprising area, Academic Comfort, and IntroversionExtroversion.

The samples in Table 1 were the criterion samples used in constructing female occupational scales for the various scientist groups, mathematicians, and engineers. Each occupational group mean was compared to the female R\&D manager mean. Engineers were higher than R\&D managers on the Realistic theme (55 vs 50 ) and chemists were higher on the Investigative theme than $R \& D$ managers ( 62 vs 58 ). However, the overwhelmingly consistent difference was the higher level which R\&D managers exhibited on the Enterprising theme relative to every sceintific group as well as mathematicians ( 46 vs $39,42,40,40$, and 41 , respectively). Engineers and R\&D managers were no different on the Enterprising theme. R\&D managers were also higher on the Conventional theme than biologists and geologists ( 50 vs 46 and 46 ).

Since the Enterprising theme was a consistent discriminator, the related Basic Interest Scales were examined. Inspection of these scales indicates that Merchandising, Sales and particularly Business Management are contributing to the general Enterprising theme difference. Business Management in particular is considerably higher for $R \& D$ managers than scientists and mathematicians ( 48 vs $39,42,41,39$, and 41 ). 


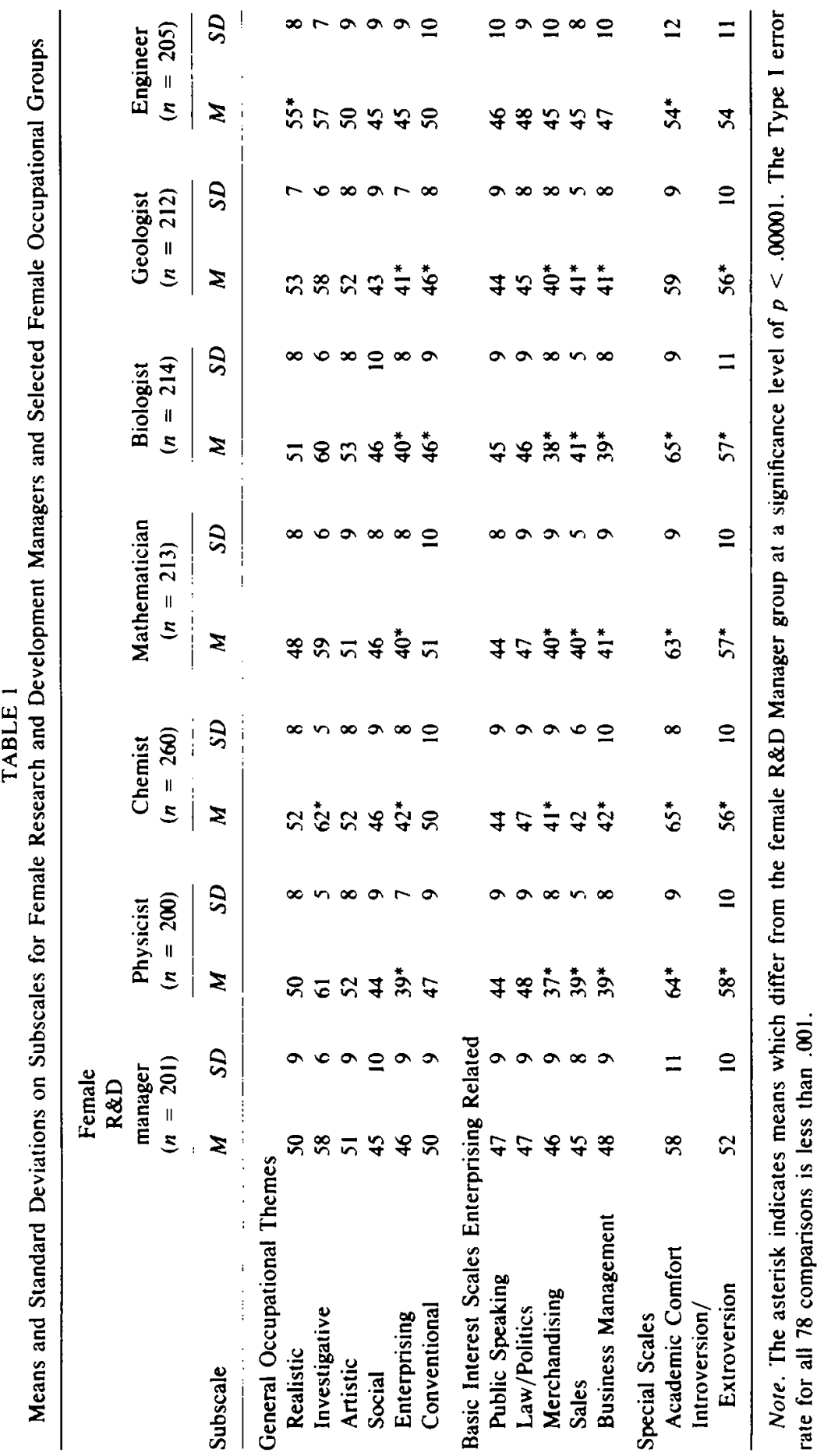


Academic Comfort means are generally higher for scientists (close to 64 in all cases except geologists) than R\&D managers (58), but engineers are lower (54) than R\&D managers. Connected with this is a consistently stronger trend toward introversion among scientists (close to 57 in most cases) compared to R\&D managers (52). Engineers and R\&D managers are not significantly different on Introversion-Extroversion.

Table 2 shows means and standard deviations for female R\&D managers and compares them to means for male $R \& D$ managers and nontechnical managers on General Occupational Themes and all Basic Interest Scales.

Inspection of the General Occupational Theme standard score means indicates female R\&D managers score lower on the Realistic theme than male R\&D managers and nontechnical managers ( 50 vs 58 and 55). However, both $R \& D$ manager groups would be labeled "moderately high" if compared to their same-sex distributions. Therefore, using their own norms, male and female R\&D managers might be considered more similar on the Realistic theme. This is a rather difficult interpretive issue, but the position taken here is that standard scores are derived from a mixedsex norm group, and the scales represent unidimensional constructs. Therefore, the means for females and males will be compared directly without extensive reference to single-sexed norms. For the Artistic theme the female standard score mean is higher than male R\&D or nontechnical manager means (51 vs 45 and 47, respectively). It appears that the Realistic and Artistic differences here are essentially reflecting the usual genderbased endorsement rates on these scales.

On the enterprising theme nontechnical managers score higher than female and male R\&D managers (53 vs 47 and 47). And a last significant difference involves the Investigative theme where both female and male R\&D managers score higher than nontechnical managers (58 and 59 vs 51).

In reporting on the Basic Interest Scales, means will always be listed in the same order as they appear in Table 2 (Female R\&D manager, male R\&D manager, and nontechnical manager). The Basic Interest Scale differences are essentially the same as those reflected by the General Occupational Themes. In the Realistic area females generally have lower standard scores than male R\&D managers and nontechnical managers on Adventure (49 vs 54 and 54), Military Activities (47 vs 51 and 56), and Mechanical Activities (52 vs 60 and 53). The Nature scale reverses this trend with females scoring higher than the male groups (54 vs 49 and 48). These differences on the Realistic Basic Interest Scales are partly a result of a heavy concentration of life science majors among the female criterion group and engineering majors in the male $R \& D$ group.

In the Investigative area, both $R \& D$ manager groups score higher than nontechnical managers on Science (60 and 61 vs 49) and Mathematics (59 and 61 vs 53). The Artistic area Basic Interest Scales of Mu- 
TABLE 2

Means and Standard Deviations for R \& D Managers and Nontechnical Managers on General Occupational Themes, Basic Interest Scales, and Special Scales

\begin{tabular}{|c|c|c|c|c|c|c|}
\hline \multirow[b]{2}{*}{ Scale } & \multicolumn{2}{|c|}{$\begin{array}{c}\text { Female R\&D } \\
\text { managers } \\
(n=201)\end{array}$} & \multicolumn{2}{|c|}{$\begin{array}{c}\text { Male } R \& D \\
\text { managers } \\
(n=215)\end{array}$} & \multicolumn{2}{|c|}{$\begin{array}{c}\text { Nontechnical } \\
\text { managers }^{a} \\
(n=1036)\end{array}$} \\
\hline & $M$ & $S D$ & $M$ & $S D$ & $M$ & $S D$ \\
\hline \multicolumn{7}{|l|}{ General Occupational Themes } \\
\hline Realistic & 50 & 9 & $58^{*}$ & 8 & $55^{*}$ & 11 \\
\hline Investigative & 58 & 6 & 59 & 6 & $51^{*}$ & 9 \\
\hline Artistic & 51 & 9 & $45^{*}$ & 10 & $47^{*}$ & 11 \\
\hline Social & 45 & 10 & 46 & 8 & 48 & 10 \\
\hline Enterprising & 46 & 8 & 47 & 9 & $53^{*}$ & 9 \\
\hline Conventional & 50 & 9 & 51 & 8 & 50 & 9 \\
\hline \multicolumn{7}{|l|}{ Basic Interest Scales } \\
\hline Agriculture (R) & 50 & 9 & 52 & 9 & 52 & 10 \\
\hline Nature $(R)$ & 54 & 8 & $49^{*}$ & 9 & $48^{*}$ & 11 \\
\hline Adventure (R) & 49 & 10 & $54^{*}$ & 8 & $54^{*}$ & 9 \\
\hline Military Activity (R) & 47 & 8 & $51^{*}$ & 9 & $56^{*}$ & 12 \\
\hline Mechanical Activity & 52 & 9 & $60^{*}$ & 7 & 53 & 11 \\
\hline Science (I) & 60 & 6 & 61 & 6 & $49^{*}$ & 10 \\
\hline Mathematics (I) & 59 & 8 & 61 & 6 & $53^{*}$ & 10 \\
\hline Medical Science (I) & 54 & 8 & 52 & 8 & 50 & 8 \\
\hline Medical Service (I) & 48 & 8 & 46 & 8 & 45 & 8 \\
\hline Music/Dramatics (A) & 51 & 9 & $44^{*}$ & 9 & $47^{*}$ & 11 \\
\hline $\operatorname{Art}(A)$ & 52 & 9 & $43^{*}$ & 9 & $45^{*}$ & 11 \\
\hline Writing (A) & 50 & 9 & $45^{*}$ & 10 & 47 & 11 \\
\hline Teaching (S) & 48 & 10 & 50 & 8 & 47 & 10 \\
\hline Social Service (S) & 44 & 9 & 43 & 8 & 46 & 9 \\
\hline Athletics (S) & 46 & 8 & $52^{*}$ & 9 & $53^{*}$ & 10 \\
\hline Domestic Arts (S) & 51 & 9 & $42^{*}$ & 8 & $43^{*}$ & 10 \\
\hline Religious Activities (S) & 45 & 9 & 46 & 9 & 47 & 10 \\
\hline Public Speaking (E) & 47 & 9 & 48 & 9 & $53^{*}$ & 10 \\
\hline Law/Politics (E) & 47 & 9 & 50 & 9 & $54^{*}$ & 9 \\
\hline Merchandising (E) & 46 & 9 & 44 & 8 & $52^{*}$ & 9 \\
\hline Sales (E) & 45 & 8 & 47 & 8 & $52^{*}$ & 10 \\
\hline Business Management (E) & 48 & 9 & 50 & 8 & $57^{*}$ & 9 \\
\hline Office Practices (C) & 46 & 8 & 45 & 9 & 45 & 7 \\
\hline \multicolumn{7}{|l|}{ Special Scales } \\
\hline Academic Comfort & 58 & 11 & $53^{*}$ & 12 & $44^{*}$ & 13 \\
\hline Introversion- & & & & & & \\
\hline Extroversion & 52 & 10 & 53 & 10 & $48^{*}$ & 11 \\
\hline
\end{tabular}

Note. A significance level of .00001 was applied to each individual comparison, and the overall significance level for 62 comparisons is therefore less than .001 .

a Adapted with permission from D. P. Campbell and E. Van Velsor (1985). The use of personality measures in the leadership development program (p. 20). Greensboro, NC: Center for Creative Leadership.

${ }^{*} p<.00001$. 
sic/Dramatics, Art and Writing are again all higher for the female group than the male groups, except Writing, where there appears to be no difference between females and nontechnical managers (47 vs 50 ). On the Social area scale of Athletics, both male R\&D managers and nontechnical managers score higher than females (46 vs 52 and 53), but the reverse is true of Domestic Arts (51 vs 42 and 43). To a large degree, these latter differences may be related to differential sex-linked endorsement rates.

The more intriguing scales are in the Enterprising area since they are related to management. The striking pattern here is the high degree of similarity between male and female R\&D managers, but elevated interest levels on the part of nontechnical managers on all scales (Public Speaking, Law/Politics, Merchandising, Sales, and Business Management). Business Management exhibits especially dramatic differences (48 and 50 vs 57).

Finally, females are higher on the Academic Comfort Special Scale than either of the male groups ( 58 vs 53 and 44), but nontechnical managers are more extroverted (lower on Introversion-Extroversion; 52 and 53 vs 48 ).

\section{DISCUSSION}

In Study 1, an assessment of scale items which were popularly endorsed or rejected indicated a heavy investment in scientific and technical domains and a rejection of the social and artistic domains. When 105 occupations were scored on the female $R \& D$ manager scale, more refined inferences could be made based on which occupational groups were similar and dissimilar. Inspection of these groups again suggested female R\&D managers are heavily invested in science, mathematics, and technical work, but are rejective of routine clerical work, any type of "attendant" work, one-on-one helping, and interpersonally nurturant occupations.

Their leadership style has a quality of professionalism and is task oriented rather than social-emotional. Furthermore, their interest in management and leadership is apparently animated by its connection to the scientific, investigative domain. Leadership and management occupations which contained the Investigative theme in their Holland codes were ranked higher than those which did not.

The vocational interest scale for female $R \& D$ managers had reasonable reliability and validity and can serve a useful purpose in assisting individuals and organizations faced with making decisions regarding the career transition from technical specialist to R\&D manager. Selection of $R \& D$ managers from available technical personnel has always been problematic for R\&D organizations. Zaleznik, Dalton, and Barnes (1970) have noted the high degree of ambivalence many scientists experience when promoted into management, and have documented a variety of dysfunctional outcomes for individuals when an inappropriate decision is made. Badawy 
(1983) also documents the strains in this transition by noting R\&D managers are in a unique role which requires them to balance professional and bureaucratic ideologies; in Holland's framework they must blend the Investigative and Enterprising domains. Furthermore, many are ill-equipped for subjective decision making, or new interpersonal demands. In addition, technical specialists may be introverted whereas management requires more extroverted functioning; the specialist usually wants to maintain close contact with science and engineering, yet management makes this difficult at best. And the specialist may overanalyze problems at the expense of action. In short, some of the traits which lead to success in technical work lead to difficulty in managerial work. Thus, a specific counseling tool, and better understanding of the vocational interests of female R\&D managers, can be quite useful in coping with the difficult human resource management challenge of assisting in the career development of women scientists and engineers.

In Study 2, the comparison of female R\&D managers to female technical specialist groups in Table 1 was corroborative of the findings in Study 1. That is, what essentially separates $R \& D$ managers from the scientific and mathematical specialists is not an overwhelming interest in the Enterprising domain on the part of managers. Rather, R\&D managers have a moderate interest level in this domain, while scientists and mathematicians are highly rejective of the Enterprising theme and related Basic Interest Scales, notably Business Management.

Reviewing the entire pattern for female R\&D managers in Table 1 shows they are strikingly similar in their interest pattern to female engineers. This is somewhat unexpected, since only $10 \%$ of the female R\&D manager criterion sample were engineers. It is interesting, however, that engineers are typically characterized as more likely to have managerial aspirations than scientists (Badawy, 1982) and are also likely to experience less strain in the career transition from technical specialist to manager. Thus, female R\&D managers appear to augment their basic scientific and technical identity with a managerial interest pattern. Scientific and managerial domains are difficult to integrate psychologically, yet female R\&D managers have apparently incorporated this general polarity between science and management into their interest structures, with managerial interests being subservient to scientific interests.

Last, Table 2 presents some rather interesting evidence supporting the essential equivalence of female and male $R \& D$ managers in terms of their interest structures. On the scales which are most pertinent to management (Enterprising theme and related Basic Interest Scales), both R\&D manager groups are equivalent. This supports the trend noted earlier in this paper that male and female managers are similar in terms of their psychological functioning, particularly as it pertains to managerial work. The differences which do exist in the Realistic and Artistic domains 
are well documented by prior studies, but have no particular relation to management.

The comparison to nontechnical managers is also informative. Nontechnical managers are lower in the Investigative area as would be expected; however, they are highly elevated in the Enterprising area relative to R\&D managers. This higher elevation in the Enterprising area is associated with more extroverted, dominant behavior, which is typically associated with managerial work (Campbell et al., 1970). However, the intriguing aspect of these relative patterns is the notion that being moderately dominant is more adaptive for $R \& D$ managers than being highly dominant. Autonomy is of deep concern to professionals, and the technical leader must be very careful in trying to balance the conflicting demands of autonomy and control in research and development settings. McCall (1981) refers to technical leaders as creators of "controlled freedom," and suggests that effective R\&D managers must establish a set of conditions under which decision making is shared, but not given away, and autonomy is partially preserved. The psychological functioning of technical manager thus contains a simultaneous "loose-tight" property by which they are capable of staying loose whole getting on with it. McCall $(1981$, p. 22) elaborates on this delicate balance by suggesting that technical leadership involves "rearranging priorities, changing sequences, and responding to the ebb and flow of events. It's letting (technical specialists) do what they are good at while influencing them through pace, timing, and order. It is taking self-directed people and giving them little nudges in the right direction."

Thus, the evidence from Table 2 is that female and male R\&D managers are homogeneous in those traits which are pertinent to management. And at the same time, they are differentiated from nontechnical managers by being less Enterprising and more Investigative. This is an adaptive pattern for R\&D managers, however, since "overmanaging" is a potential liability for technical managers.

\section{REFERENCES}

Badawy, M. K. (1982). Developing managerial skills in engineers and scientists: Succeeding as a technical manager. New York: Van Nostrand-Reinhold.

Bailyn, L. (1985). Autonomy in the industrial R\&D lab. Human Resource Management, 24, $129-146$.

Brief, A. P., \& Oliver, R. L. (1976). Male-female differences in work attitudes among retail sales managers. Journal of Applied Psychology, 61, 526-528.

Buros, O. K. (Ed.). (1978). Mental measurements yearbook (8th ed.). Highland Park, NJ: Gryphon.

Campbell, D. P. (1971). Handbook for the Strong Vocational Interest Blank. Stanford, CA: Stanford Univ. Press.

Campbell, D. P., Dunnette, M. D., Lawler, E. E., \& Weick, K. E. (1970). Managerial behavior, performance and effectiveness. New York: McGraw-Hill.

Campbell, D. P., \& Van Velsor, E. (1985). The use of personality measures in the leadership development program. Greensboro, NC: Center for Creative Leadership. 
Donnell, S. M., \& Hall, J. (1980). Men and women as managers: A significant case of no significant differences. Organizational Dynamics, 8, 60-77.

Fitzgerald, L. F., \& Betz, N. E. (1983). Issues in the vocational psychology of women. In S. A. Osipow \& J. B. Walsh (Eds.), Handbook of vocational psychology (Vol. 1, pp. 83-159).

Gough, H. G. (1984). A managerial potential scale for the California Psychological Inventory. Journal of Applied Psychology, 69, 233-240.

Hansen, J. C., \& Campbell, D. P. (1985). Manual for the SVIB-SCII (4th ed.). Stanford, CA: Stanford Univ. Press.

Hennig, M., \& Jardim, A. (1977). The managerial woman. Garden City, NY: Doubleday.

Hill, R. E., \& Roselle, P. F. (1985). Differences in the vocational interests of research and development managers versus technical specialists. Journal of Vocational Behavior, 26, 92-105.

Holland, J. L. (1985). Making vocational choices: A theory of careers. Englewood Cliffs, NJ: Prentice-Hall.

Kotter, J. P. (1982). The general managers. New York: Free Press.

McCall, M. W. (1981). Leadership and the professional. Greensboro, NC: Center for Creative Leadership.

McClane, H. (1980). Selecting, developing and retaining women executives. NY: Van Nostrand-Reinhold.

Miner, J., \& Miner, J. (1977). Motivation to manage. Atlanta, GA: Organizational Measurement Systems Press.

Neter, J., \& Wasserman, W. (1974). Applied linear statistical models. Homewood, IL: Irwin, Inc.

Norman, C. (1983). Broad public support found for R \& D. Science (Washington, D.C.), 222, 1311.

Tilton, J. W. (1937). The measurement of overlapping. Journal of Educational Psychology, 28, 656-662.

U.S. Department of Labor (1982) Occupational outlook handbook. Bureau of Labor Statistics.

Zaleznik, A., Dalton, G., \& Barnes, L. (1970). Conflict and orientation in careers. Boston, MA: Harvard Graduate School of Business Administration.

Zytowski, D. G., \& Warman, R. E. (1982). The changing use of tests in counseling. Measurement and Evaluation in Guidance, 15, 147-152.

Received: July 22, 1985. 